\title{
Povos ancestrais, América do Sul e Caribe: epistemologias e poéticas visuais na formação de engenheiros
}

\author{
Ancestral people, South America and Caribe: \\ epistemologies and visual poetics in the Enginnering formation
}

Janina Mirtha Gladys Moquillaza SANCHEZ1

\begin{abstract}
Resumo
Objetivos desta reflexão: tornar conhecidas epistemologias e estéticas visuais de povos ancestrais da América do Sul e Caribe, visando re-escrever a história da Engenharia dessa parte do mundo; oferecer imagens de soluçóes dadas a problemas de engenharia e arquitetura, demonstrando a importância epistemológica e estética para a condição humana. Com base teórica em Bachelard (2006), teoria e metodologia mitohermenêutica, analisa-se o trajeto antropológico e ao mesmo tempo mudança epistemológica de alunos, pela construçáo de projeto de pesquisa. Concluindo, questiona-se o fato do Brasil jamais ter considerado necessário a população não indígena aprender epistemologias e estéticas ancestrais. Propóe-se a criar Rede de Conhecimentos.
\end{abstract}

Palavras-chave: Epistemologia de Povos Ancestrais. América do Sul e Caribe. Formação em Engenharia. Rede de Conhecimentos.
Abstract

This reflection aims: to make known South America and Caribean ancestral aesthetics and epistemology, re-writing Engineering history to this part of the world; to offer images of architecture and engineering solutions, demonstrating the importance of epistemology and aesthetics to the human condition. Based on Bachelard's theories (2006), mythhermeneutics theory and methodology, the anthropological path is analysed so as the experience of epistemological change of students by Project based learning. Concluding, we find questionable that Brazil never considered the need of non-indigenous people learning from ancestral epistemology and aesthetics. The creation of a Net of Knowledge is proposed.

Keywords: Ancestrals People Epistemology. South America and Caribe. Engineering Formation. Net of Knowledge.

1 Pós-doutora em Antropologia da Educação pela Faculdade de Educação da Universidade de São Paulo (FE-USP) (2010). Pesquisadora Associada ao Lab-Arte da FE-USP. End.: Rua A, 89. Praia do Cumbuco, Caucaia, Ceará. CEP: 61619260. Cel.: (85) 981147534 Email: <janinasanches@gmail>.

R. Educ. Públ. v. 27

n. $65 / 2$

p. $713-731$ maio/ago. 2018 


\section{Introdução}

Esta é uma reflexão sobre experiência docente e pesquisa realizada com alunos do primeiro semestre do curso de engenharia, de 2013 a 2017, em um centro universitário do nordeste do Brasil. Trata-se de contribuição da área de Humanidades à formação de engenheiros, visando atender requisito do MEC/2002 e, dessa forma, buscando alterar a epistemologia colonizada comumente usada para essa formação profissional. Dois objetivos nos orientaram: a) Contribuir para o reconhecimento da estética e epistemologia de povos ancestrais da América do Sul e Caribe, visando reescrever a história da Engenharia nessa parte do mundo; b) Oferecer conhecimentos sobre esses povos ancestrais, por meio de imagens que mostram soluçóes dadas a problemas de engenharia e arquitetura, dando a perceber que os seus criadores desenvolveram um saber ou epistemologia e a importância desse reconhecimento para a condição humana. Pela teoria adotada, com base epistemológica em Bachelard (2006), pelos estudos do imaginário cultural, de Gilbert Durand (2002), e pela teoria e metodologia mitohermenêutica (SANTOS, 2003; SANCHEZ, 2010, 2011, 2012, 2016), desvela-se a complexidade no trajeto antropológico (MORIN, 2002) e como afeta a condição humana. Ao mesmo tempo, analisa-se a experiência de mudança epistemológica dos alunos, pela construção de projeto de estudo e pesquisa. Pelos resultados encontrados, discute-se sobre a não linearidade da ciência e práticas da diversidade epistemológica. Concluindo, questiona-se o fato de em nosso país jamais ter se considerado a necessidade da população não indígena conhecer e aprender sobre a estética e as epistemologias de povos ancestrais dessa regiáo ao sul do globo e propôe-se a criação de uma Rede de Conhecimentos.

\section{0 trajeto antropológico da formação de engenheiros no Brasil: reflexões}

O alcance filosófico deste trabalho tem suporte teórico em Bachelard (1884-1962) (2006), epistemólogo francês com trânsito poético, crítico da unidade do conhecimento racionalista, linear, da concepção unitária da ciência vinda do século XVII, e defensor da reflexão sobre a reflexão como conhecimento científico, em detrimento do conhecimento comum, construído pela ingenuidade da percepção imediata, direta, sobre o objeto de estudo. Ele perguntava se seria mesmo possível traçar as fronteiras do conhecimento científico: 
"Estaremos nós, verdadeiramente encerrados num domínio objetivamente fechado?” (BACHELARD, 2006, p. 23). Diante do mistério do real, sustentava Bachelard, a alma não pode fazer-se ingênua, pois "[...] face ao real, aquilo que se julga saber claramente, ofusca aquilo que se deveria saber" (BACHELARD, 2006, p. 166).

Tomo como objeto de estudo a formação de engenheiros no Brasil, considerada a partir da exigência de contribuição da disciplina Humanidades, Ciências Sociais e Cidadania, responsabilidade que assumi de 2013 a 2017. Além disso, considere-se o desafio de atender ao marco da Resolução CNE/ CES, do MEC/2002, que define os princípios, fundamentos, condiçóes e procedimentos para a formação de engenheiros, consistindo em, conforme o seu Art. $4^{\circ}$ :

- item 9 - que futuros engenheiros devem estar habilitados para atuar em equipes multidisciplinares;

- item 10 - que devem compreender e aplicar a ética e responsabilidade profissional;

- item 11 - que devem saber avaliar o impacto das atividades da engenharia no contexto social e ambiental.

Nesse sentido, escolhi para minha abordagem da disciplina a perspectiva da complexidade (MORIN, 2002), assumindo a hipótese de que essa formação tem trazido no interior de si mesma o mundo cósmico, físico, químico, o mundo vivo. Ao mesmo tempo, tem se mantido separada deles pelo pensamento positivista fechado, em sequência, lógico, imediato, da cultura dominante. A experiência lançou-me na aventura de buscar elementos para integrar conhecimentos, esclarecer as consequências da exclusão e colaborar para a mudança na maneira de conhecer, vinda do senso comum, para a epistemológica, habilitando para reflexôes da ciência contemporânea. Nesse sentido, os alunos construíram projetos de pesquisa, tomando como problema o impacto de obras de engenharia por eles mesmos escolhidas no Ceará e confrontando-as à reflexão teórica dos Direitos Humanos, pois, como sustentava Bachelard, é preciso restituir à ciência todos os seus interesses filosóficos: "[...] é o esforço de racionalidade e de construção que deve reter a atençáo do epistemólogo" (2006, p. 167), dizia o autor, sustentando que o que distingue o trabalho do epistemólogo do historiador das ciências é que o historiador toma as ideias como fatos e o epistemólogo toma os fatos como ideias, inserindo-as num sistema de pensamento. 
Ao distinguir os valores privilegiados pelo paradigma positivista até então dominante no contexto curricular, situados no chamado Regime Diurno das estruturas antropológicas do imaginário (DURAND, 2002), encontramos que se tem favorecido um viés epistemológico colonizado e sua linha de saberes, ignorando e até menosprezando outras, mais antigas e próximas a nós, conhecimentos desenvolvidos por povos vizinhos e povos nativos do Brasil que tem sido deliberadamente excluídos. Afirma Morin (2002, p. 39), que "[...] novas descobertas váo ainda modificar o nosso conhecimento, mas pela primeira vez na história o ser humano pode reconhecer a condição humana no seu enraizamento e no seu desenraizamento." Considerados elementos de cultura, "[...] subtraídos do seu significado epistemológico, os conhecimentos ancestrais, esforços para responder a questóes" (BACHELARD, 2006, p.166), técnicas e práticas em engenharia, têm ficado fora dos livros didáticos, e essa exclusão deixa consequências sociais que afetam a formação presente e futura de engenheiros e de todo cidadão.

Em seu capítulo para o livro Contribuiçóes para a História da Engenharia no Brasil (1994), o engenheiro e professor da Politécnica da USP, Francisco de Paula Dias de Andrade, expôs o viés epistemológico hegemônico por ele adotado, abrindo também a discussão sobre a questão da autoria individual versus autoria coletiva, própria dos povos nativos, e o reconhecimento da complexidade envolvida. Defendia o autor que a Ciência da Engenharia e a Arte da Arquitetura nasceram na cultura grega, ambas contendo o grande ideal de verdade e beleza, próprios de Atenas. Segundo o professor Andrade, tendo assim fundamentado a ciência intuitiva da proporção, os gregos aplicaram raciocínios abstratos, chegando a dimensionar espessuras, pesos, quantidades e medidas. Eles teriam criado a geometria, que os levou ao conhecimento da verdade das organizaçóes estruturais do espaço e ao dimensionamento de peças resistentes, com as quais "[...] trabalhavam seus engenheiros e arquitetos as relaçōes de ordem, proporção, formas harmoniosas, dando a seus edifícios expressão artística.” (ANDRADE, 1994, p. 33). Segundo o autor, destacase Eupalinos de Megara, que viveu durante o século VI a.C., construtor do aqueduto de um quilômetro de extensão, que levaria água à sua cidade, tendo esse engenheiro sido celebrado por esse feito durante toda a antiguidade. Atualmente fechada, em desuso, a obra, declarada patrimônio da humanidade pela Unesco, consta nos livros como a origem da engenharia. 


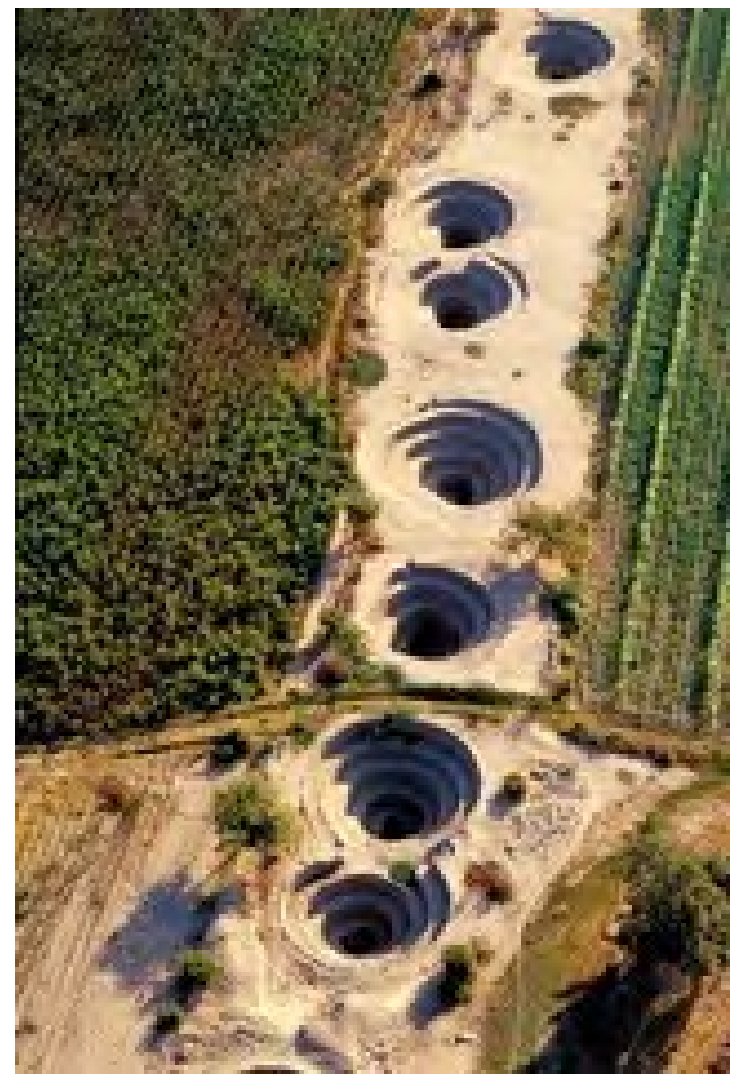

Fonte: Disponível em: <https://www.google.com.pe/search?q=foto+aqueduto+de+nazca\&rlz=1C1CHZL_pt>

Acesso em: 2 ago. 2017.

Porém, nesse lado ao sul do mundo, a imagem que vemos agora, é de um aqueduto subterrâneo de cinco quilômetros de extensão, que foi construído em Nasca, na região de Ica, ao sul do Peru, até agora em funcionamento. Qualquer um de nós que viajar ao Peru pode ir ao aqueduto e com suas próprias mãos sentir a água cristalina que corre no seu fluxo. Segundo estudiosos das antigas povoaçôes peruanas, a cultura nasca existiu aproximadamente entre o ano 600 a.C e o ano 600 d.C., tendo dado continuidade à cultura Paracas, que existiu entre o ano 700 a.C e o 200 a.C. Como sabemos, o significado atribuído a uma realização qualquer não pertence à natureza intrínseca dessa realização, mas é devido às atribuiçóes que são dadas pelas pessoas a essa realização, ou seja, o significado é dado pelo imaginário de um grupamento humano, em determinado contexto histórico, econômico, social, político, cultural. Os nasca (600 a.C - 600 d.C) trabalhavam integrando o ser humano no cosmos, 
foram grandes conhecedores da astronomia, primorosos construtores de aquedutos e sistemas de canais numa regiâo sujeita a terremotos pela Falha de Nasca, e muitos aquedutos estáo atualmente ainda em uso, como Matara, Ocaña, Copara, Tejeje e La Achirana. Eles levavam água aos vales, assim incorporando extensas áreas de terra para o desenvolvimento da agricultura, dentro do deserto. Portanto, a primeira pergunta que faço é: podemos dar o nome de engenharia ao aqueduto de Nasca, do qual perdeu-se o nome do autor do projeto e dos trabalhadores da obra coletiva? Os aproximadamente 400 alunos de engenharia, que ao longo dos últimos quatro anos participaram dessa disciplina responderam que sim, reforçando a minha defesa da sua inserção na História da Engenharia.

Para alguns estudiosos, os desenhos dos nasca guardam características da estética Paracas, anterior à nasquense. Esses desenhos cobrem grandes extensóes do deserto local, levam o nome de Lineas de Nasca e devido ao tamanho da sua extensão somente podem ser vistos à altura do voo de um aviáo. Os diversos desenhos representam constelaçóes de estrelas do céu e, por exemplo, o macaco corresponde à chamada Ursa Maior.

Fotos 2 e 3 - Desenhos do calendário astronômico de Nasca

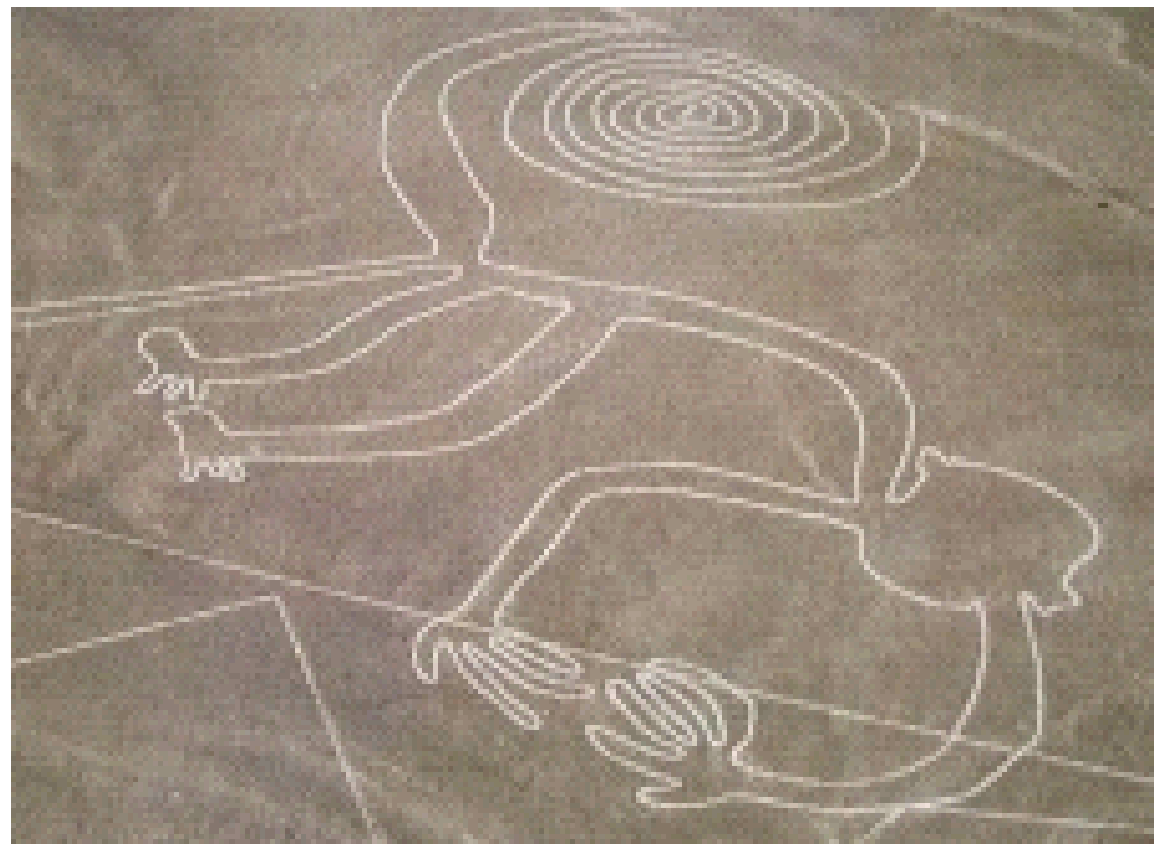




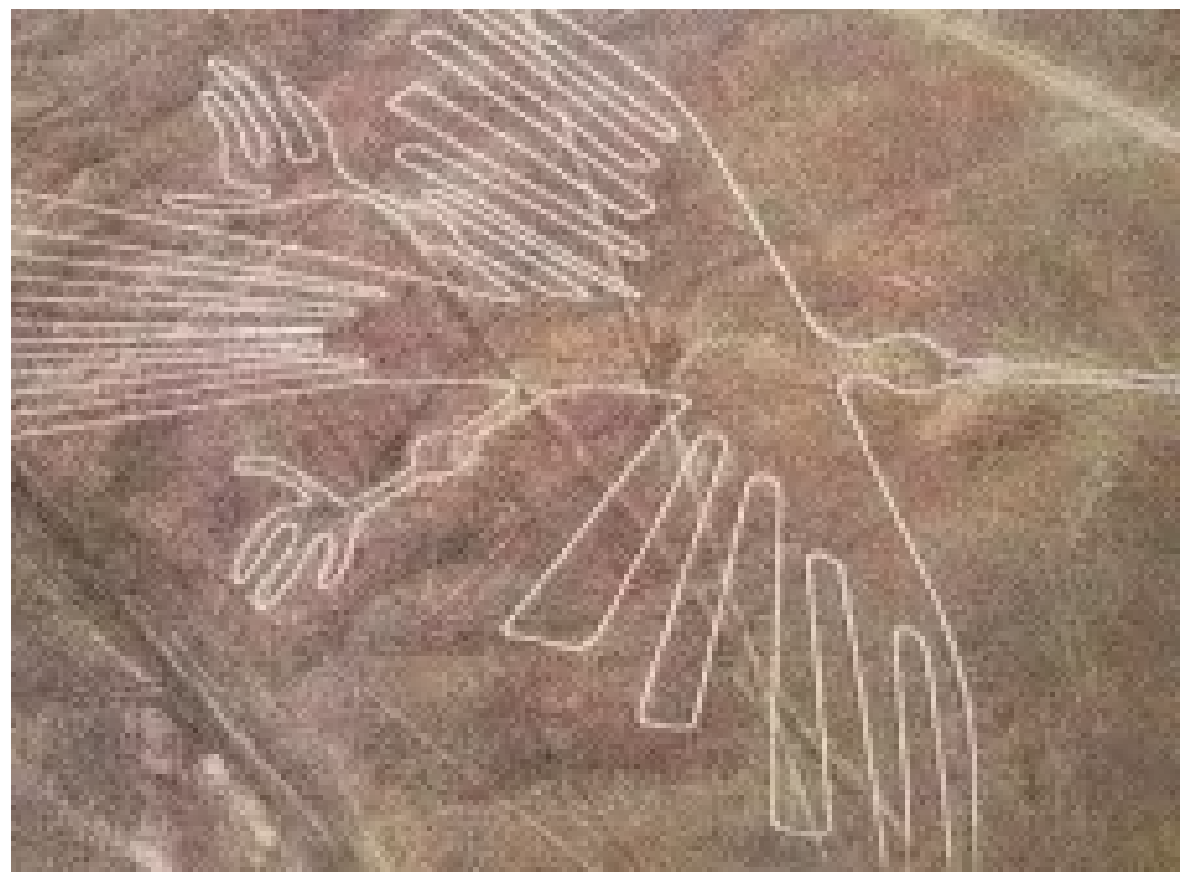

Fonte: Disponível em: <https://blogcatedranaval.com/2015/03/6/la-dama-de-nazca-y-el-calendario-astronomico/> Acesso em: 2 ago. 2017

Acredita-se que astrônomos, sacerdotes e outros sábios estudaram e traçaram o movimento das estrelas para auxiliá-los a prever os períodos de plantar, colher e preparar-se para outros fenômenos da natureza, como as consequências das chuvas que em certa época do ano descem dos Andes em enxurrada para o deserto. Assim, criaram um complexo observatório linear no cháo, para a leitura dos que fariam a intermediação entre a natureza e os seres humanos. $\mathrm{O}$ fato dos desenhos terem permanecido com o mesmo traçado durante tantos séculos é explicado pelo alto conteúdo de ferro das pedras que configuram os desenhos, em contraste com o traçado em baixo relevo que os contorna. Sendo essa uma região desértica, o sol incandescente sobre o material ferroso dificulta que a areia assente. Falamos, portanto, sobre o uso de conhecimentos que aprendemos a chamar astronomia, geometria, matemática, química, física, engenharia agrícola, design, e essa constatação levou-me à segunda pergunta: de fato, o fazer ciência dos ancestrais peruanos e o seu planejamento estratégico seriam motivo para defender que o ser humano supóe, analisa, relaciona, compreende e constrói conhecimento por diferentes lógicas, uso de diferentes códigos e linguagens? Meus alunos vibraram com essa constatação. E não tenho dúvidas quanto a isso, nem quanto à manipulação do que se considera conhecimento válido, nas relaçóes de poder. 
A imagem a seguir é do portal de acesso ao templo Kalasasaya de Tiwanaku, tendo em frente uma escultura de $7.30 \mathrm{~m}$ de altura por $1.20 \mathrm{~m}$ de largura, que faz parte da estética da arquitetura Tiwanaku e existiu entre o ano 1500 a.C e o ano 1.000 a.C. Eles trabalhavam a metalurgia do cobre, prata e ouro. Sabe-se que era um estado imperial com uma rede de centros administrativos, cidades-satélites, colônias econômicas, armazéns, canais, sistemas de distribuição, e a massa da população era empregada na execução de grandes obras públicas. Muitos de seus edifícios estavam situados conforme indicaçóes da astronomia (MACEDO, 2005).

\section{Foto 4 - Templo Tiwanaku}

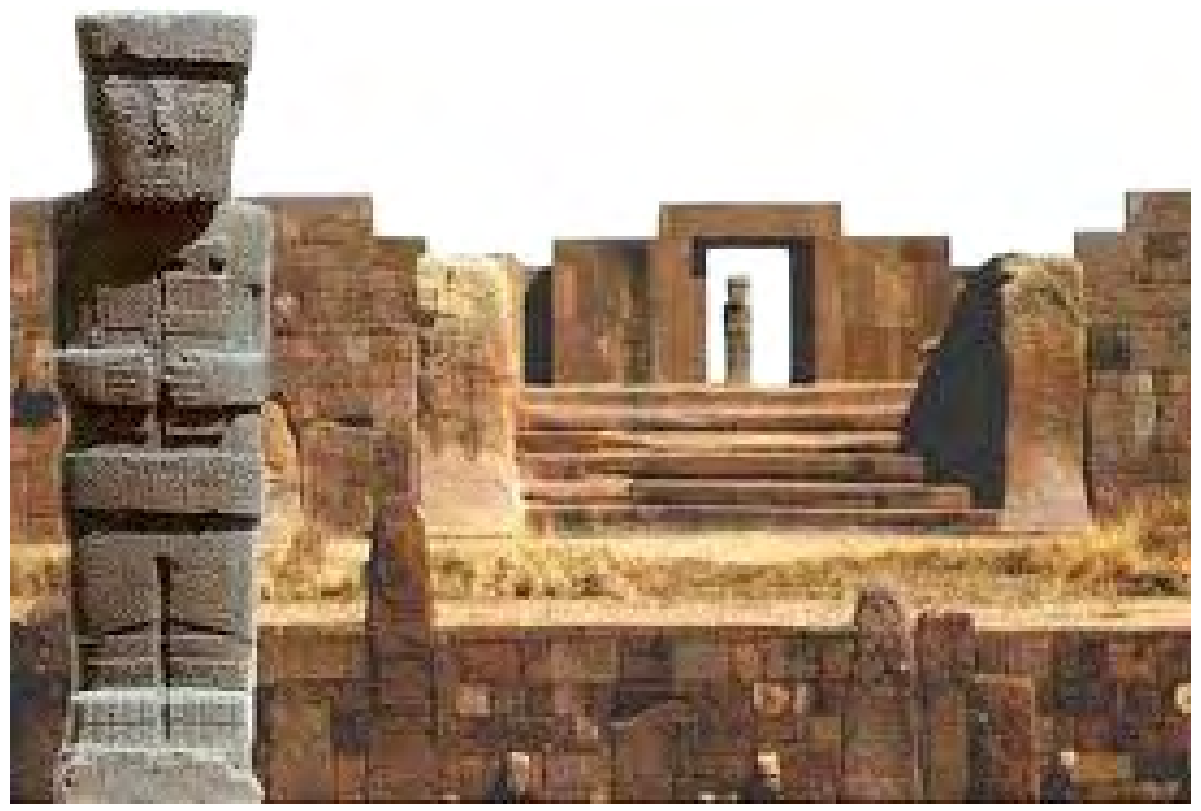

Fonte: Disponível em: <https://es.wikipedia.org/wiki/Tiahuanaco>. Acesso em: 26 jul. 2017.

Com base nessas informações e analisando a imagem dessa edificação e sua arte, penso que estamos falando dos conhecimentos que costumamos chamar estética, arquitetura, engenharia civil, engenharia de produção, administração pública. Chegar a essa noção provocou a terceira pergunta que inspira esse estudo: quantos entre nós, docentes, alunos universitários e profissionais da arquitetura, engenharia e da educaçáo superior no Brasil, conhecem sobre epistemologias e poéticas visuais da América do Sul e do Caribe? Durante o tempo que trabalho com a disciplina semestral no curso de engenharia, apenas quatro alunos tinham ouvido falar sobre o tema, e três já tinham viajado para algum país do leste da América do Sul. A maioria 
planeja viajar para os Estados Unidos da América do Norte ou para países europeus, atendendo à atualização de um poderoso marketing de turismo. Nada contra essas fascinantes paragens, mas por que permanecemos sem nos conhecer? Em 2016, fui convidada para dar aula aberta no curso de arquitetura da mesma instituição em que ensino. Docentes e alunos jamais tinham ouvido qualquer informação sobre esses povos serem autores de qualquer tipo de edificação, antes da chegada dos europeus. Portanto, pensar a disciplina tem sido também refletir sobre uma introdução a conhecimentos que anteriormente alunos e docentes náo tiveram acesso.

Quando me refiro à estética da arquitetura e da arte aqui apresentada é porque reconheço uma filosofia da arte que está presente nas imagens que mostram ter feito parte de uma vida plena de significados. Vemos representaçóes, movimentos, mudanças, desenhos sobre realizaçôes que fizeram e fazem sentido para as pessoas e respondem a diálogos complexos em relaçóes holonômicas, configurando uma estética organizacional. A imagem a seguir, é da chamada Porta do Sol. Não vou me demorar ao analisar a perfeição da portada em suas relações arquitetônicas e astronômicas, com cada pedra pesando algumas toneladas e situadas em encaixes perfeitos, mas vou diretamente à figura central, acima da portada, do deus solar Wiracocha.

Fotos 5 e 6 - Porta do Sol com imagem do deus Wiracocha ao centro

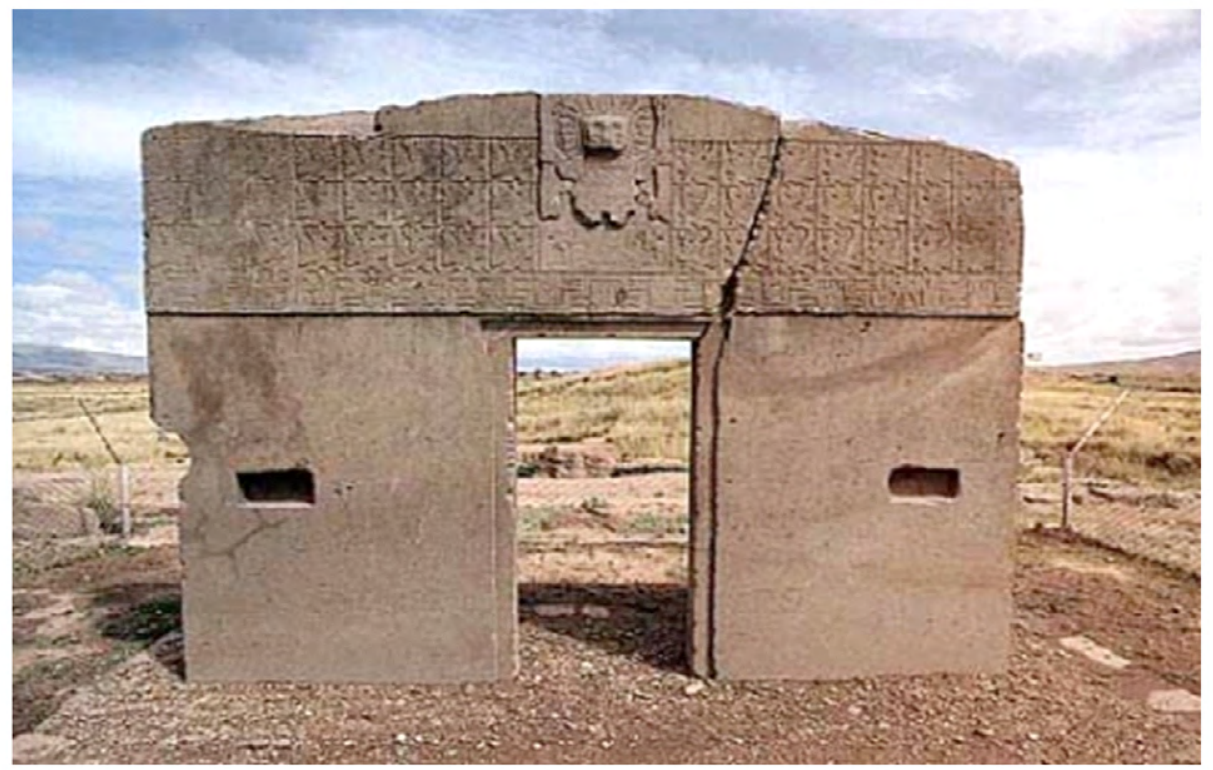

Porta de templo em Tiahuanaco, Perú. Desenho do deus hermafrodito Wiracocha. 


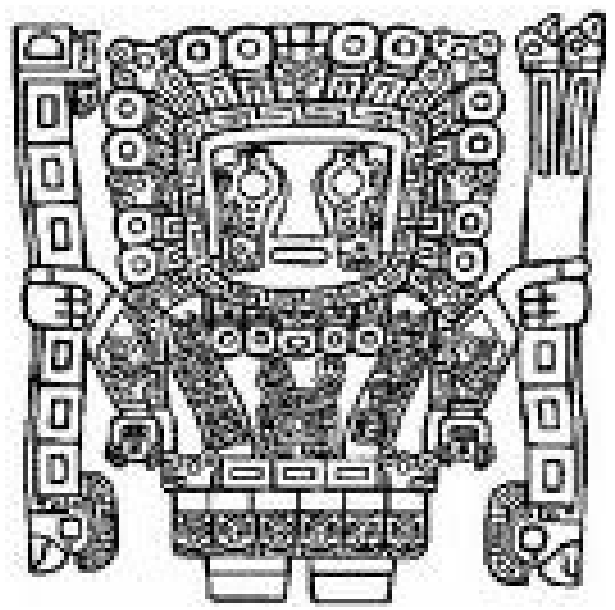

Fonte: Disponível em:<https://pt.wikipedia.org/wiki/Tiauanaco>. Acesso em: 28 jul. 2017.

O deus Wiracocha mora nas montanhas, é criador e organizador do universo e de tudo que nele existe. Conta o mito que, sendo hermafrodito, ele criou a primeira mulher, sua irmã gêmea, simbolizando a mãe terra, e organizou o universo em três mundos: o Hanan Pacha, mundo de cima, onde habitam os astros, constelaçóes, estrelas; o Kay Pacha, mundo dos seres terrestres, montanhas, lagos, pessoas, animais, plantas; e o Uchu Pacha, mundo interior ou subterrâneo - simbolizado pela serpente, onde vivem os mallquis, sementes ou ancestrais enterrados, para que nasçam pessoas novas na terra. A análise mitológica dessa simbologia, entre outras interpretaçóes, nos transporta à figura do hermafrodito, que é Hermes para os Gregos, Mercúrio para os romanos, Shiva para os indianos, Osíris para os egípcios, e nos defronta com a atualidade da questão social de gênero, objeto do estudo de Norbert Elias (1990) e Michel Foucault (2007). Segundo esses autores, a noção de gênero que vivemos seria consequência social da polarização provocada pelos interesses da industrialização, ou seja, as atribuiçóes para o gênero masculino de força, determinação, poder, e para o gênero feminino de docilidade, submissão, fragilidade e pouca inteligência, reconhecidas como se fossem atributos naturais e não criaçóes sociais que atendem a interesses de poder. Atualizando essa distorção, mulheres na engenharia são sujeitadas a salários mais baixos que dos homens, assédio moral, sexual, ao preconceito apoiando violências simbólicas sofridas no exercício da profissão (MACHADO et al., 2015). A atualização da engenharia como campo profissional masculino e da mulher como incapaz de assumir essa profissão de homem resulta em stress (MENDONÇA, NASCIMENTO, SILVA, 2014). 
Também a matemática, importante para a engenharia, é objeto de preconceito: geralmente nas avaliaçóes internacionais PISA, alunos dos países ao sul do globo se saem mal. Por que será? Muitos anos antes da vinda dos europeus a esse continente, os maya, que ocupavam o leste do México e a Guatemala, usavam um sistema de numeraçáo coletiva, complexa, de raiz mista, que agrupava de $20 \mathrm{em} \mathrm{20.} \mathrm{Algumas} \mathrm{inscriçóes} \mathrm{mostram} \mathrm{somas} \mathrm{que}$ atingem milhões. Sem a matemática, não teria sido possível administrarem grandes cidades-estado, com armazéns, hospitais, área comercial, área para os dirigentes da organização das cidades, mercado, periferias e outros conjuntos de edificaçóes. Calcularam o ano com 365 dias, tendo o erro de 24 horas a cada quatro anos. Há registros oficiais dos conquistadores, que sacerdotes como Diego de Landa mandaram queimar as antigas inscriçôes. Suas obras de arquitetura e engenharia são mundialmente admiradas por profissionais de diferentes áreas.

\section{Fotos 7 e 8 - México arqueológico}

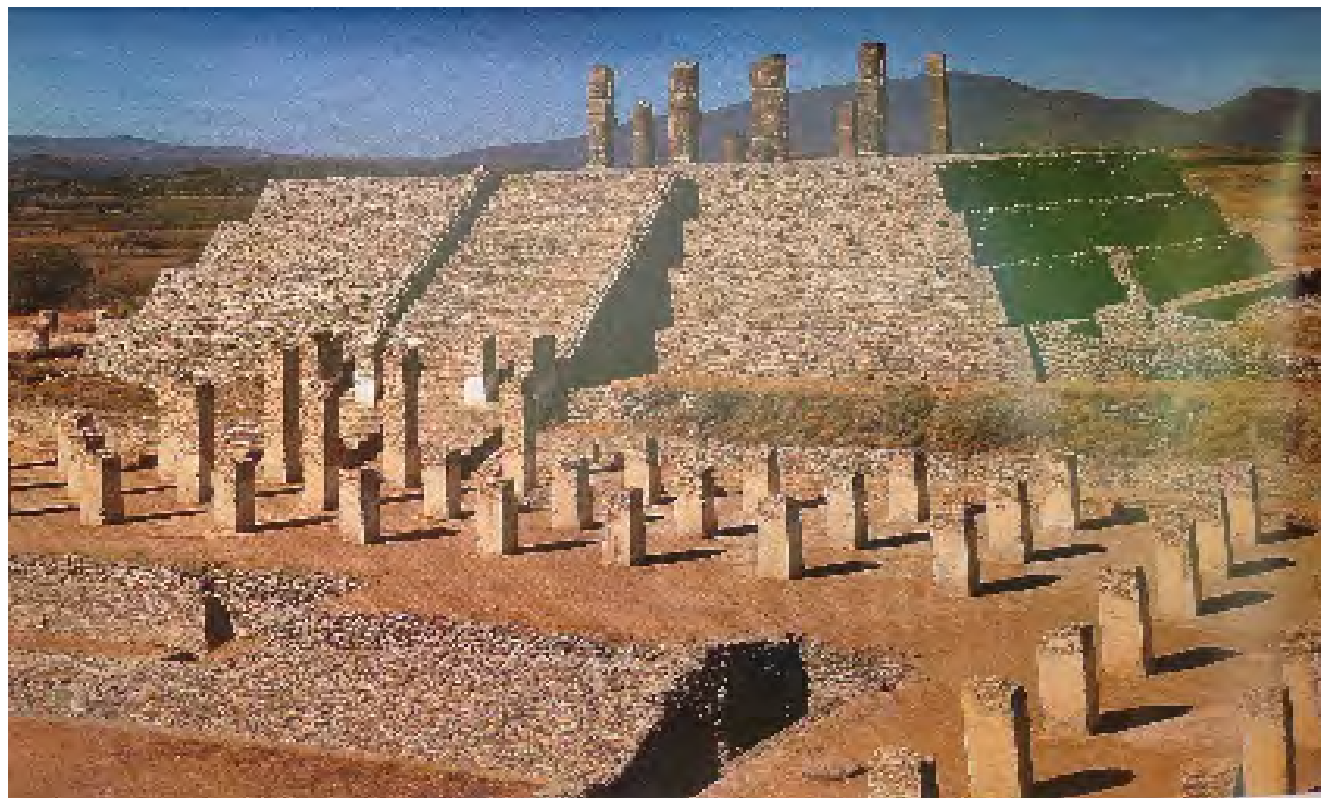



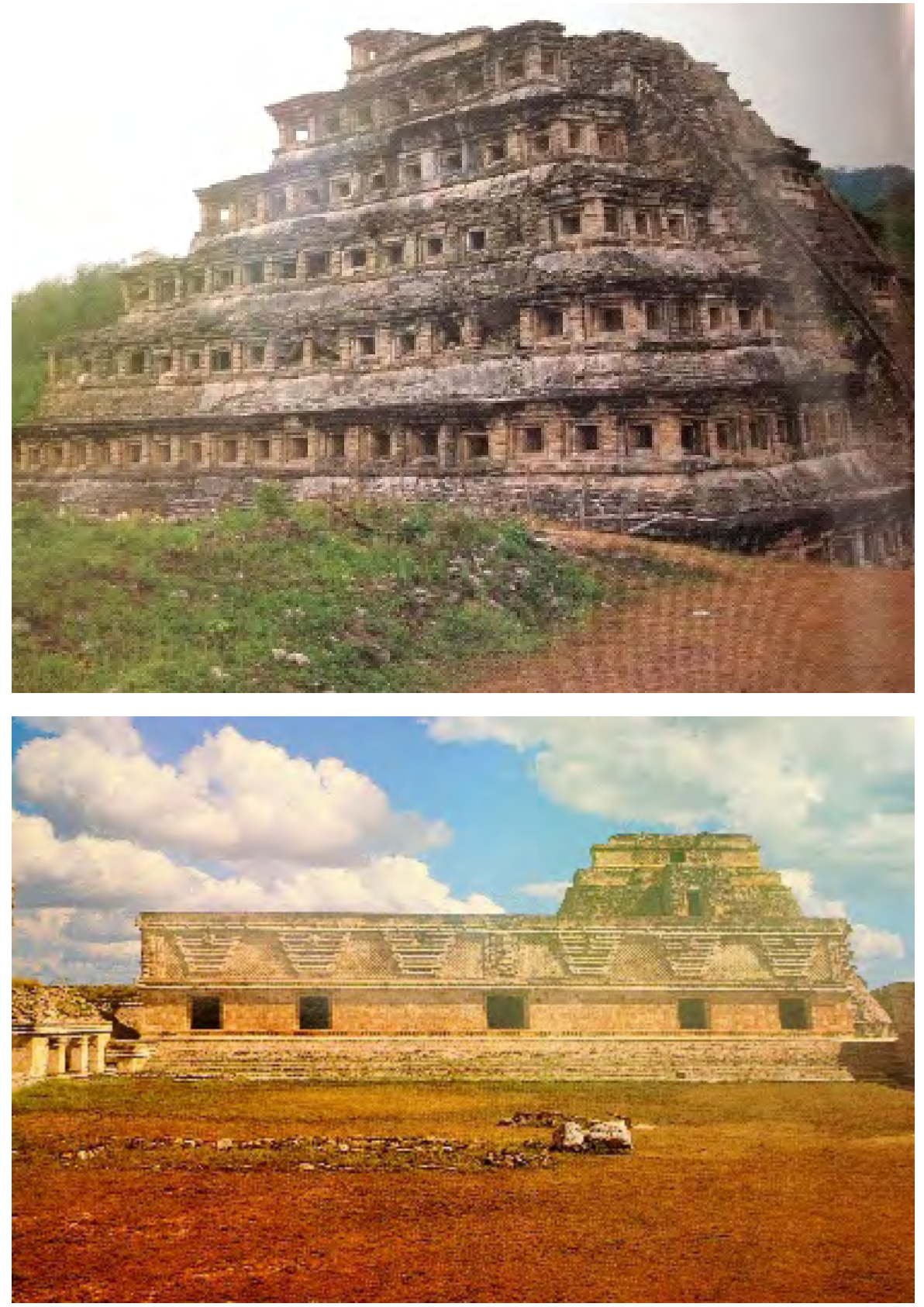

Fonte: Márcia Castro Leal (1995, p.1, 30, 77). 
Arquitetos atuais desenham esses conjuntos de edificaçóes ancestrais existentes no México, cuja estética bastante se assemelha à arquitetura moderna do século XX, linhas simples, algumas vezes em curva, dialogando com a natureza, construçóes em direção ao norte, dialogando em direção ao sul com outra edificação e, no intermeio do trajeto, o vento leste-oeste, uma passagem interposta por pequenas construçóes ou simplesmente o vazio do espaço. Pondo em discussão a dinâmica ideológica da história da engenharia construída oficialmente para os povos desse continente ao sul do globo, desvelando as relaçóes de poder e as políticas que movem a educação pública e privada em nosso país, percebemos a necessidade de didática pedagógica conscientizadora sobre a não linearidade e a diversidade epistemológica do ser humano, assim como reconhecer que as pressóes do colonialismo intelectual têm encontrado as condiçóes ideais para sua atualização e adaptação (SANCHEZ, 2010). Nesse sentido, essa reflexão teórica metodológica mitohermenêutica, com base em Gilbert Durand (2002), visa contribuir na conscientização sobre estruturas antropológicas de imaginários ao mesmo tempo profundamente significativos, não lineares, reflexóes e soluçóes diferentes para os mesmos problemas humanos. $\mathrm{Na}$ ancestralidade das imagens aqui discutidas, penso que satisfizeram necessidades humanas, como: conhecer, que constitui o Ser ao refletir e conseguir responder a questôes propostas; a fundamental, de afetividade na forma de cidadania, do amor ético ao contexto e à comunidade com quem se convive; manter vínculos, relaçóes interpessoais, fazendo parte de um grupo maior do qual se orgulhar; criar, construindo bem-viver (não no sentido de ter coisas, mas no sentido espiritual, na vida coletiva), ou Sumak Kawsay, como se diz em quéchua.

\section{0 método: mitohermenêutica na formação de engenheiros e engenheiras e interpretação dos resultados encontrados}

Metodologicamente, esta reflexão mitohermenêutica levou-me ao mito grego de Sísifo, que quer apressadamente subir a montanha e volta a subila repetidamente, sem nunca conseguir chegar ao topo. Assim observo nossos engenheiros na situação atual, profissionais ansiosos, apressadamente desejando atingir a riqueza e a fama, entregando-se ao imediatismo, ao egoísmo, à vaidade fugaz e até à corrupção, desdenhando o alimento espiritual e a afetividadeética disponível no fazer da sua encantadora profissão. Recorrendo às estruturas antropológicas do imaginário (ALVARENGA, 2007; BRANDÂO, 2010; DURAND, 2002) e relacionando aos mitos gregos, romanos, da Índia, do Egito aos do Perú, mayas, aztecas, busquei nas divindades o esclarecimento sobre a dinâmica dos arquétipos, querendo visualizar melhor a complexidade do sistema 
simbólico cultural presente e suas representações. Na mitologia grega encontra-se o símbolo da engenharia, a deusa Minerva, contraditoriamente, representando uma profissão de homens para homens. Conta a mitologia grega que às margens do rio Tritão nasceu a deusa Atená - Minerva para os romanos - da cabeça de seu pai, o deus Apolo, que havia engolido a mãe da criança, Métis (deusa da prudência e da sabedoria), pensando que assim evitaria o nascimento do filho ou filha. Porém, por ocasiáo do nascimento da criança, as fortes dores de cabeça provocadas em Apolo, deus dos deuses, eram insuportáveis, como são dolorosas as mudanças e as transformaçóes. Nascida no corpo masculino, não tendo vivenciado a infância que lhe seria oferecida pela mãe e que lhe fortaleceria o corpo, Atená nasceu adulta, independente, racional, agressiva, portadora de autoridade (ALVARENGA, 2007), dentro de um corpo frágil, protegido por capacete, escudo, lança e armadura. Na humanização do arquétipo, ela foi tomada para símbolo da engenharia. A evolução da consciência humana fez dela protetora das normas, leis, da socialização, das inteligências e do viver na cidade.

Do processo de especialização da industrialização do século $\mathrm{XX}$, observa-se um legado de disjunção e desarticulação dos saberes, deixado pelas circunstâncias do positivismo, que fragilizou a formação de engenheiros, levando-os a excluírem a sensibilidade, a reflexão estética e a diversidade epistemológica de sua formação, criando uma intelectualidade colonizada e fechada. Atenta a essa circunstância, desenvolvi esse esforço teórico-metodológico holonômico, portanto, integrador. Em decorrência da discussão que me propus para esse debate, sobre o fato dos currículos de nosso país jamais terem considerado a necessidade da população não indígena conhecer e aprender sobre epistemologias e estéticas de povos ancestrais dessa regiáo ao sul do globo, pergunto: se tivessem construído esse conhecimento ao longo de sua vida profissional, os docentes, os alunos e engenheiros profissionais teriam aceitado passivamente a satisfação grosseira com que são destruídas aldeias, plantas, animais, prostituídas mulheres, crianças e subjugados líderes nativos, pelo impacto de obras de engenharia no interior do Brasil?

Radicalizando, caberia a pergunta extrema: com qual lado o futuro engenheiro se identifica? Com o lado dos interesses das empresas empreiteiras, que visam ao lucro imediato para satisfaçóes egoístas? Ou com as populaçóes, plantas, rios e animais, que dáo continuidade à vida? Sabemos que não se trata de radicalizar, polarizar, gerando outros tipos de violências que reduzem a vida, mas, pela prática das inteligências coletivas e da cidadania, encontrar meios que integrem e beneficiem os processos de transformação da formação em engenharia. Como resultados encontrados nas avaliaçóes semestrais, os alunos destacaram a surpresa causada pela forma como a disciplina foi trabalhada por meio da construção de projeto coletivo de pesquisa, a provocação ao relacionamento interpessoal e 
comprometimento na construção de um conhecimento questionador, dialógico, o desenvolvimento da noção de moral social, a conscientização sobre impactos da engenharia na sociedade. O mito grego de Sísifo revelou o engenheiro que trabalha com muito esforço, sem olhar para os lados, sem deixar-se viver a dádiva de dar, receber, deixar-se amar por suas realizaçóes. Querendo chegar apressadamente ao topo, ficar rico e famoso, assim começa outra e outra vez a subir a montanha.

No trajeto antropológico observou-se, por um lado, a força dos jogos de poder, as pressóes da velocidade da tecnologia, o imediatismo, a administraçáo pública por egoísmo, vaidade, desdém ao Outro, produzindo corrupção. Simbolicamente, a profissão é importante, porém os rastros de destruição que deixa nas populaçóes do interior do Brasil, povos nativos e meio ambiente, nos fazem perguntar: importante, para quem?

Tomando para amostra alguns trabalhos dos alunos, faço a análise mitohermenêutica, conforme o Quadro 1, a seguir:

\section{Quadro 1 - Trabalhos de alunos, descrição e análise mitohermenêutica}

\begin{tabular}{|c|c|c|}
\hline Título & Descrição do trabalho de pesquisa & $\begin{array}{l}\text { Breve análise } \\
\text { mitohermenêutica }\end{array}$ \\
\hline $\begin{array}{l}\text { 1. Impacto do Complexo } \\
\text { Industrial e Portuário } \\
\text { do Pecém (CIPP) nas } \\
\text { populações tradicionais. } \\
\text { Anacé: aproximadamente } \\
2.000 \text { pessoas. }\end{array}$ & $\begin{array}{l}\text { Processos de desapropriações. Mobilização } \\
\text { indígena e recomendação do Min. Público, } \\
\text { os Anacé e seu pleito pela regularização } \\
\text { de território passou a ser entrave para } \\
\text { a instalação da refinaria e a ampliação } \\
\text { do CIPP. Até 2011: obras paradas. } \\
\text { Consequências danosas para os indígenas. }\end{array}$ & $\begin{array}{l}\text { Prevalece Regime } \\
\text { Diurno das imagens: } \\
\text { interesses de poder, } \\
\text { egoísmo, ganha a } \\
\text { corrupção e não a } \\
\text { obra ou os benefícios } \\
\text { para população e o } \\
\text { ecossistema. }\end{array}$ \\
\hline $\begin{array}{l}\text { 2. Impactos da } \\
\text { Transposição do Rio São } \\
\text { Francisco, Ceará. } \\
\text { Na população Anacé, } \\
\text { aprox. } 2000 .\end{array}$ & $\begin{array}{l}\text { Obra iniciada em 2007, entrega prevista } \\
\text { 2010-a-12. Parte inaugurada em } 2017.0 \\
\text { custo aumentou } 71 \% \text {. Perda do emprego } \\
\text { da população nas regiões desapropriadas } \\
\text { e dos trabalhadores ao término das } \\
\text { obras. Modificação do ecossistema. } \\
\text { Desapropriações e remoções. Circulação de } \\
\text { trabalhadores por terras indígenas: Truká, } \\
\text { Tumbalalá, Pankararu, Anacé, Tuxá, Pipipã, } \\
\text { Kambiwá, Xocó e Kariri-Xocó, localizados } \\
\text { nos estados da Bahia, Pernambuco, } \\
\text { Sergipe, Alagoas e Ceará. }\end{array}$ & $\begin{array}{l}\text { Prevalece Regime } \\
\text { Diurno das imagens: } \\
\text { interesses de poder, } \\
\text { egoísmo, ganha a } \\
\text { corrupção e não a } \\
\text { obra ou os benefícios } \\
\text { para população e o } \\
\text { ecossistema. }\end{array}$ \\
\hline
\end{tabular}




\begin{tabular}{|l|l|l|}
\hline Título & Descrição do trabalho de pesquisa & $\begin{array}{l}\text { Breve análise } \\
\text { mitohermenêutica }\end{array}$ \\
\hline $\begin{array}{l}\text { 3. Impacto das Rodovias } \\
\text { BR- 020, BR-222, CE-090, } \\
\text { CE-085 na população } \\
\begin{array}{l}\text { Tapeba. } \\
\text { Aprox. 6.600 pessoas. }\end{array}\end{array}$ & $\begin{array}{l}\text { Os Tapeba têm sofrido os impactos da } \\
\text { urbanização. Seu território é cortado pelas } \\
\text { rodovias BR-020, BR-222, CE-090 e CE-085 } \\
\text { - uma ferrovia, rede elétrica de alta tensão, } \\
\text { gasoduto, aqueduto, indústrias, invasão de } \\
\text { loteamentos, violência urbana. }\end{array}$ & $\begin{array}{l}\text { Prevalece Regime } \\
\text { interesses de poder, } \\
\text { egoísmo, ganha a } \\
\text { corrupção e não a } \\
\text { obra ou os benefícios } \\
\text { para população e o } \\
\text { ecossistema. }\end{array}$ \\
\hline $\begin{array}{l}\text { 4. As desigualdades na } \\
\text { construção civil: marcando } \\
\text { as diferenças de raça, } \\
\text { gênero e social. }\end{array}$ & $\begin{array}{l}\text { Segregações no ambiente de trabalho } \\
\text { são objeto de pesquisas de mestrado e } \\
\text { doutorado. Separação por raça: a maioria } \\
\text { dos cargos de salário mínimo está com } \\
\text { pessoas da raça negra e povos nativos; } \\
\text { separação de gênero, mulheres-homens } \\
\text { não têm o mesmo status. }\end{array}$ & $\begin{array}{l}\text { Prevalece Regime } \\
\text { Diurno das imagens: } \\
\text { segregação, } \\
\text { separação entre as } \\
\text { pessoas devido aos } \\
\text { jogos de poder. }\end{array}$ \\
\hline $\begin{array}{l}\text { 5. Transporte de carvão } \\
\text { no porto do Pecém e } \\
\text { consequências para } \\
\text { habitantes da cidade de }\end{array}$ & $\begin{array}{l}\text { O carvão, produto mais importado via o } \\
\text { Porto do Pecém. Durante dois anos a Ceará } \\
\text { Portos pagou multas à prefeitura por danos } \\
\text { ambientais e doenças causadas pela poeira } \\
\text { de carvão espalhada no transporte até a } \\
\text { Termoelétrica do Pecém. Em abril de 2017, } \\
\text { o IBAMA aplicou multa de 13 milhões de } \\
\text { reais. A empresa parou e repensa o projeto. }\end{array}$ & $\begin{array}{l}\text { Prevalece Regime } \\
\text { imarno das } \\
\text { e mens: egoísmo } \\
\text { em detrimento } \\
\text { da satisfação no } \\
\text { cumprimento de um } \\
\text { bom projeto. }\end{array}$ \\
\hline
\end{tabular}

Fonte: Quadro elaborado pela autora.

\section{Reflexões finais}

A exclusão de saberes tão importantes desenvolvidos por grupamentos humanos ancestrais, conhecimentos ausentes em todos os níveis curriculares de ensino fundamental, médio e universitário no Brasil, tem consequências para a condição humana. Afeta o sentido de Ser, a Identidade como um todo, pois conhecer a própria história é direito humano, mas também o sentido de afetividade como cidadania e ética em relação à comunidade e ao contexto em que se vive. Igualmente é afetado o sentido de pertencimento a um grupo maior, do qual poderia se orgulhar, assim como o sentido de criar e construir para o bem-estar coletivo (Sumak Kawsay em quéchua), como é a prática 
comunitária dos povos nativos da América do Sul e Caribe. Há muito para aprender, usar, ampliar e divulgar. Proponho criar uma Rede de Conhecimentos, disponibilizando estudos de mestrado, doutorado e pós-doutorado já existentes nas universidades dessa região e outros que virão. Acredito que neste momento de reconstrução da natureza e do ser humano em todo o mundo será de grande valia mapear os modos de conhecer, as lógicas civilizatórias, as estratégias de sustentabilidade, os modos de relaçóes com o meio ambiente, técnicas desenvolvidas para a compreensão da vida cósmica, dos solos, plantas, animais, das pessoas nas relaçóes interpessoais.

E mudar o currículo oficial em nosso país, quem sabe afetando também os países vizinhos, propiciando a interação entre docentes e pesquisadores da América do Sul e Caribe, ressignificando a didática pedagógica na perspectiva intercultural, a partir de contribuição de natureza formativa, não metodológica, que inclui intercâmbio de aspectos epistemológicos e de poéticas visuais, e, por extensão, afetando as políticas públicas, valorizando a condição humana, nossa história e nosso futuro, significa romper com a violência simbólica que diz separa e reinarás. É também superar o gesto simbólico da construção do palácio do arcebispo europeu, erguido sobre o palácio do Inca Roca no século XVI (Foto 9):

\section{Foto 9 - Palácio do arcebispo, construído sobre o palácio do Inca Roca. Cusco, Perú}

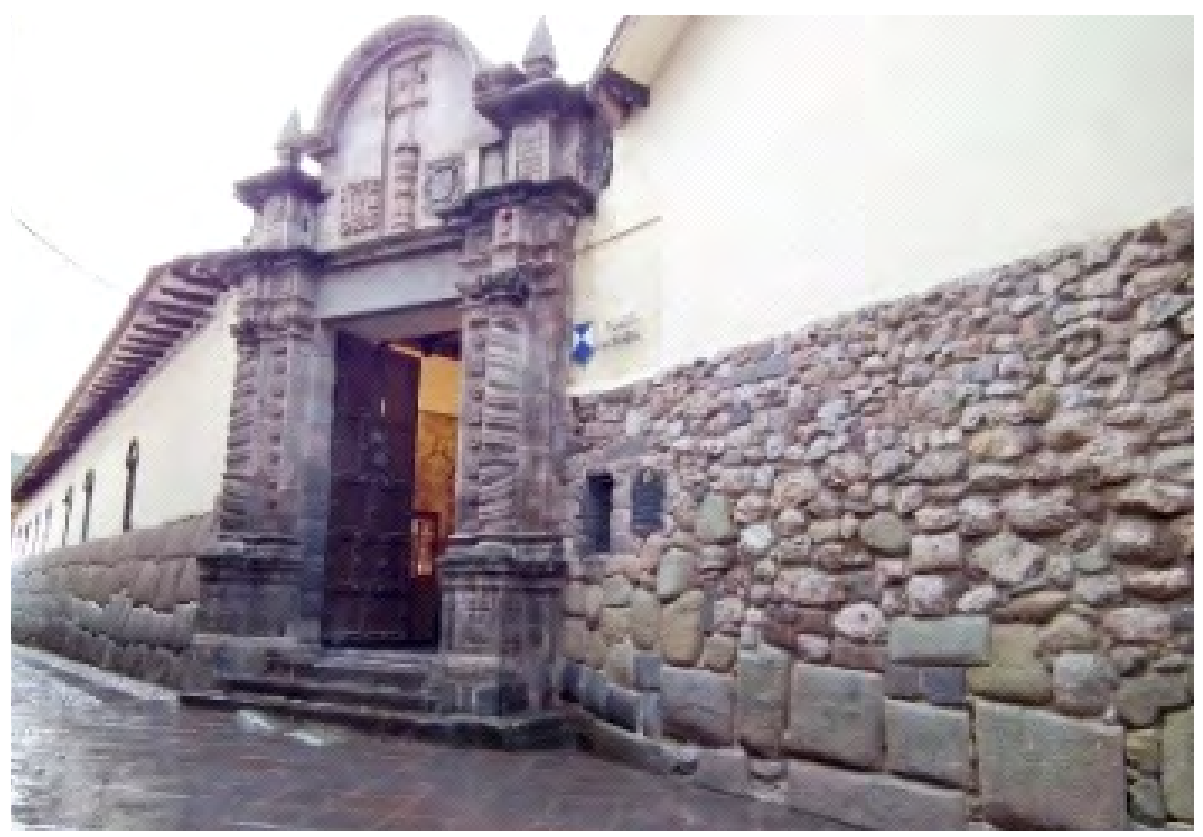

Fonte: Disponivel em: <https://www.google.com.pe/search?ei=Ag7RWpulH4XCwATBqYHgDg\&q=cusco+pal\%C3\%A 1cio+del+arcebispado+en+cusco>. Acesso em: 26 jun. 2017. 
Com essa imagem, recheio o meu coração de esperança na construção cultural do currículo para a formação de engenheiros, com outras dinâmicas simbólicas em nosso sistema sul americano de significação. Longe de modelos epistemológicos colonizados, acredito nas possibilidades interculturais, multiprofissionais e novos espaços para significar, valorizando nossos conhecimentos ancestrais.

\section{Referências}

ALVARENGA, M. Z. (Org.) Mitologia simbólica. São Paulo: Casa do Psicólogo, 2007. ANDRADE, F. P. D. A construção de edifícios. In: VARGAS, M. Contribuiçóes para a história da engenharia no Brasil. São Paulo: EDUSP, 1994.

BACHELARD, Gaston. A epistemologia. Tradução de F. L. Godinho e M. C. Oliveira. Lisboa: Ed. 70, 2006. Disponível em: <https://bibliotecadafilo.files. wordpress.com/.../bachelard-gaston-a-epistemologia.pdf>. Acesso em: 10 set. 2017. BRANDÃO, Junito de Souza. Mitologia grega. 17. ed. Petrópolis: Vozes, 2010. v. III BRASIL. MEC. Resoluçáo CNE/CES no. 11, de 11 de março de 2002. Art. 1o. - 4o. Formação de engenheiros. Disponível em: <http://portal.mec.gov.br/ cne/arquivos/pdf/CES112002.pdf>. Acesso em: 26 jun. 2017.

DURAND, Gilbert. As estruturas antropológicas do imaginário. Introdução à arquetipologia geral. Tradução de Hélder Godinho. São Paulo: Martins Fontes, 2002.

FOUCAULT, M. História da sexualidade. O uso dos prazeres. Rio de Janeiro: Graal, 2007. v. 2.

LEAL, Márcia Castro. México arqueológico. México: Monclem, 1995.

MACEDO, J. C. Culturas Prehispanicas del Perú. Lima: Grimanesa, 2005.

MACHADO, Patricia Inez da Silva et al. Mulheres graduadas em engenharia: um estudo de caso. Revista ADMpg Gestáo Estratégica, Ponta Grossa, v. 8, n. 2, p. 35-43, 2015.

MENDONÇA, L. K.; NASCIMENTO, T. R. L. N.; SILVA, R. M. Mulheres na engenharia: desafios encontrados desde a universidade até o chão da fábrica na engenharia de produção, na Paraíba. In: REDOR, 18., 2014, Recife. Anais... Recife: Universidade Federal Rural de Pernambuco, 2014. p. 3503-3511.

MORIN, Edgar. Reformar o pensamento. A cabeça bem feita. Tradução de Ana P. de Viveiros. Lisboa: Instituto Piaget, 2002. 
PEREZ, M. P. Espaço-tempo e ancestralidade na educaçáo ameríndia: desdobramentos de Paulo Freire na província de Chimborazo, Equador. Tese (Doutorado em Educação) - Faculdade de Educação da Universidade de São Paulo - FEUSP, 2008.

PEREZ, M. P. Estudios de lo imaginario: Orígenes y trayectos. Praxis \& Saber, UPTC, Tunja, Colombia, v. 4, n. 8, p. 135- 156, 2013.

SANTOS, Marcos Ferreira. O crepúsculo do mito: mitohermenêutica e antropologia da educação em Euskal Herria e Ameríndia. Relatório de pesquisa (Livre Docência) - Faculdade de Educação da Universidade de São Paulo, 2003.

SANCHEZ, J. M. Currículo e filosofia nativa. In: CASALI, A.; CASTILHO, S. D. de (Org.). Diversidade na Educaçáo: implicações curriculares. São Paulo: EDUC, 2016. v. 1.224 p.

SANCHEZ, J. M. Direitos da Natureza. Epistemologia e escolha. Encontro Internacional Direitos Culturais, 1., UNIFOR, Fortaleza, set. 2012.

SANCHEZ, J. M. La poética de bien-vivir y derechos de la naturaleza: Sumak Kawsay. France, Versailles: Il Volantino Europeo, 34. Oct 2011, p. 23-29.

SANCHEZ, J. M. Contact and ressentment are challenges to education enhancement. Zurich: Stiftung Szondi-Institut, p. 211-219, 2010.

SANCHEZ, J. M. Mitohermenêutica do feminino na antropologia da educaçáo: interculturalidade Brasil-Perú. Relatório de pesquisa (Pós-Doutorado em Antnropologia da Educação)-. Universidade de São Paulo, FEUSP, 2010.

SANCHEZ, J. M. Currículo intercultural: a arte como sistema simbólico cultural na escola de branco. Tese (Doutorado em Educação) - Pontifícia Universidade Católica de São Paulo, PUC-SP, São Paulo, 2006.

SILVA, Mayra Rachel. Canteiro de obras, lugar de mulher? Um estudo sobre relações de gênero e trabalho na construção civil em Fortaleza, CE. Dissertação (Mestrado em Políticas Públicas e Sociedade)- Universidade Estadual do Ceará, UECE, Fortaleza, 2013. 